\title{
Prostate cancer survival in Trinidad: Is PSA a prognostic factor?
}

\author{
Kameel Mungrue, MD; Suresh Moonan, MD; Maryam Mohammed, MD; Saara Hyatali, MD
}

Department of Paraclinical Sciences, Faculty of Medical Sciences, The University of the West Indies, St Augustine, Trinidad and Tobago

Cite as: Can Urol Assoc J 2012;6:E249-E255. http://dx.doi.org/10.5489/cuaj.11006. Epub 2011 Nov 2.

\section{Abstract}

Background: Prostate cancer is the most common malignancy among men in the western hemisphere, including Trinidad and Tobago. The aim of this study is to describe the epidemiological features of prostate cancer among patients admitted to a tertiary level teaching hospital during 2002 to 2005. We assessed the longterm survival of patients with prostate cancer and the epidemiology of the disease.

Methods: We reviewed the admissions data for the period 20022005. Demographic, clinical and outcomes (survival or death) data were collected and analysed, using SPSS version 16. Statistical analysis included Kaplan-Mier survival analysis, Cox regression models and the log-rank test. A $p$ value of $<0.05$ was considered statistically significant.

Results: Of the 1250 cases reviewed, 242 participants were selected. Patients of African ancestry, older than 60 years and a Gleason score greater than 7 had an increased risk of mortality. Patients with prostate-specific antigen (PSA) $\geq 100 \mathrm{ng} / \mathrm{L}$ had a 3 -fold increased risk of mortality. Survival rates declined between 2002 and 2005.

Conclusion: This is the first study of its kind to demonstrate survival rates among patients with prostate cancer in Trinidad. The following epidemiological features were identified: average age of occurrence of 71 years, ethnic disparity with higher occurrence in African men than all other ethnic groups and a PSA of $>100 \mathrm{ng} / \mathrm{dL}$. These features were associated with a 3 -fold higher risk of death. A Gleason score of 8 to 10 was also associated with lower survival rates.

\section{Introduction}

Prostate cancer (PCa) is the most common malignancy among men in the western hemisphere. ${ }^{1}$ In Europe, about 190000 new cases occur every year with 80000 deaths. $^{2-4}$ The global incidence of PCa is 25.3 per 100 000, with a mortality rate of 8.1 per $100000 .^{1}$ It is also the most common cancer among men in Trinidad and Tobago, accounting for 349 new cases and 187 deaths yearly. ${ }^{5}$

The clinical features of PCa in men diagnosed at ages younger than 70 have changed. ${ }^{6}$ In the United States, the risk is increased in men $\geq 65 ; 80 \%$ of the cases diagnosed are within this age group. ${ }^{7}$ In Trinidad and Tobago, the population is dominated by two major diaspora: Africans (43\%) and South East Asians (45\%). In a report from the National Cancer Registry of Trinidad and Tobago for the period 2000 to $2002,77.2 \%$ of PCa patients were in the $60-84$ age group, while $10.2 \%$ were in the $25-59$ group and $12.6 \%$ were $\geq 85 .{ }^{8}$ In a study restricted to the South-Western part of the island, Ayoung-Chee and colleagues found a PCa prevalence rate of $44.4 \%$ among African men compared to $26.3 \%$ among South East Asians. ${ }^{9}$ South-East Asians had an earlier age of presentation, higher percentage of normal digital rectal examinations, lower prostate-specific antigen (PSA) titres and a higher percentage of survival.

Familial aggregation, race, alcohol consumption, exposure to ultraviolet radiation and occupational exposure are important etiological factors. ${ }^{9-12}$ Family history is important, especially with a sibling with $\mathrm{PCa}$; this situation carries a higher risk ratio (3.0-4.5) than a paternal history (risk ratio 1.9-2.3). ${ }^{13,14} \mathrm{~A}$ high-fat diet may contribute to PCa, however research continues to explore the exact nature of this risk. ${ }^{15}$ On the other hand, chemoprevention is popular. In their Canadian study, Nam and colleagues demonstrated that $26 \%$ of 155 urology clinic patients and $80 \%$ of 113 support group patients diagnosed with $\mathrm{PCa}$, or at increased risk for it, endorsed the use of preventive approaches and complementary therapies, including low-fat diet, vitamin E or garlic. ${ }^{16}$ However, the selenium and vitamin E cancer prevention trial (SELECT) showed that selenium and vitamin E supplements, taken either alone or together for an average of 5 years, did not prevent PCa. ${ }^{17}$

There are several factors which can predict the survival of patients with PCa. These include age, ethnicity, serum PSA, prostate biopsy and Gleason score. A 6-year analysis performed on PCa patients in Jamaica revealed that $31.6 \%$ of the cases had PSA values $>100 \mathrm{ng} / \mathrm{mL}$, with the remaining $68.4 \%$ showing values $<100 \mathrm{ng} / \mathrm{mL}$. This study also reported Gleason scores; $0.4 \%$ of patients had a score between 2 and $4 ; 37.5 \%$ a score between 5 and $6 ; 31.9 \%$ a score of 7 ; and $30.2 \%$ scores greater than $8 .{ }^{18}$ While there is substantial 
information about the natural history of $\mathrm{PCa}$, a review of the literature revealed no published reports on survival experience among Trinidadian men with PCa. If the ultimate goal of cancer treatment is improved survival, baseline evidence of survival rates is a critical starting point.

The aim of this study is to access the long-term survival of patients with PCa. We also describe the epidemiological features of PCa among patients admitted to the San Fernando General Hospital (SFGH), a tertiary teaching hospital serving the southern half of the island during 2002 and 2005.

\section{Methods}

This is a retrospective review of PCa patients admitted to one of the two major tertiary hospitals in Trinidad over a 4-year period. The SFGH was chosen because it serves about half of the population (650 000) in a high prevalence area and has a single urological team. Patients are screened in the community by their primary care physician and, if $\mathrm{PCa}$ is suspected, they are referred to the SFGH for confirmation of the diagnosis and treatment. At present, diagnosis is based on examination of histopathological or cytological specimens from the prostate gland. Participants were identified by reviewing the admissions register from the Urology Unit of the SFGH between 2002 and 2005. Patients with benign prostatic hypertrophy and prostatitis were excluded from the study.

Data collected by the attending physician on admission were reviewed. Data included age, ethnicity, PSA, Gleason score and outcome (i.e., survival or death at the time of completion of the study) using a pre-designed data collection form. Diagnostic biopsy reports were reviewed to validate Gleason scores. To ascertain vital status, we used two methods. First, medical records were reviewed for any documentation of death. The date of the death was used to calculate time to the event (death). Second, for patients with no record of death, the patient or his next of akin was contacted by telephone to ascertain the patient's present status (alive or dead). If the patient died, we recorded the date of death from the death certificate. The impact of treatments on survival was not part of the study as all patients were treated by the same surgical team using standard treatment regimens.

The data collected were analyzed using SPSS version 16.0 (SAS Institute, Cary, NC). Survival rates were expressed as the percentage surviving for 3 and 5 years using the KaplanMeier method. Cox proportional hazards was used to calculate the hazard ratios (HR) and 95\% confidence intervals (Cl) for risk factors, significance levels were set using a $p$ value of $<0.05$. Ethical approval for this study was obtained from the University of the West Indies Ethics Committee.

\section{Results}

A total of 1250 patients were reviewed using the admissions register. Of these, 242 patients met the criteria for entry into the study and had substantial data available. Most patients did not meet the criteria. There are several reasons for this. In the public health care system, a patient is first screened by a primary care physician; if $\mathrm{PCa}$ is suspected, the patient is referred to the hospital for diagnosis and would enter the database as a possible case of PCa. Several outcomes at this stage are possible: the patient may undergo the process and found not to have PCa; the patient may abscond prior to or after the diagnosis; or he may be lost to follow-up. In addition, all medical records are documented in hard copy. Records are stored and retrieved manually for all visits and can be easily lost or misplaced.

We enrolled patients per year (Table 1 ). We also recorded the characteristics of the 242 patients (Table 2). The bulk of disease (>90\%) occurred in the two age groups: $51-79(43 \%)$ and $\geq 70(55 \%)$ years. The ethnic distribution of PCa was significantly higher among African men than in any other ethnic group. In 2005, the proportion of Africans with disease $(68 \%)$ was almost 5 times greater than the other major diaspora South East Asians (14\%). However, Africans were older (mean age 72) than South East Asians (mean age 67), had higher Gleason scores ( $\geq 7$ vs. $\leq 6)$ and had higher mean PSA levels (54 vs. $34 \mathrm{ng} / \mathrm{mL}$ ).

Most patients (40\%) had a Gleason score of 5 to 7 , which is a good prognostic indicator of survival. However, as much as $23.5 \%$ overall had a Gleason score of 8 to 10 , which is very predictive of nodal involvement and thus lower survival. ${ }^{19}$

The mean follow-up time for survivors was 5.5 years; 67 $(26.7 \%)$ patients died. The Kaplan-Meier survival curves for the years 2002-2005 showed changing survival rates by year (Fig. 1). Patients diagnosed in 2003 and 2004 had similar survival rates, however there was a large difference in survival rates for 2002 and 2005. The log-rank test compared survival data of 2002 with 2005 and found a statistically significant difference $(p<0.032)$. The probability of survival at 3 years ranged from 0.78 for 2005 to 0.95 for 2002 . Similarly, the probability of survival at 5 years ranged from 0.72 for 2005 to 0.88 for 2002 .

\begin{tabular}{ll}
\hline Table 1. Enrolment, 2002-2005 & \\
\hline Year & No. \\
\hline 2002 & 47 \\
2003 & 44 \\
2004 & 94 \\
2005 & 57 \\
Total & 242 \\
Mean age at diagnosis & 71 \\
Median age at diagnosis & 72 (range: 34-89) \\
\hline
\end{tabular}




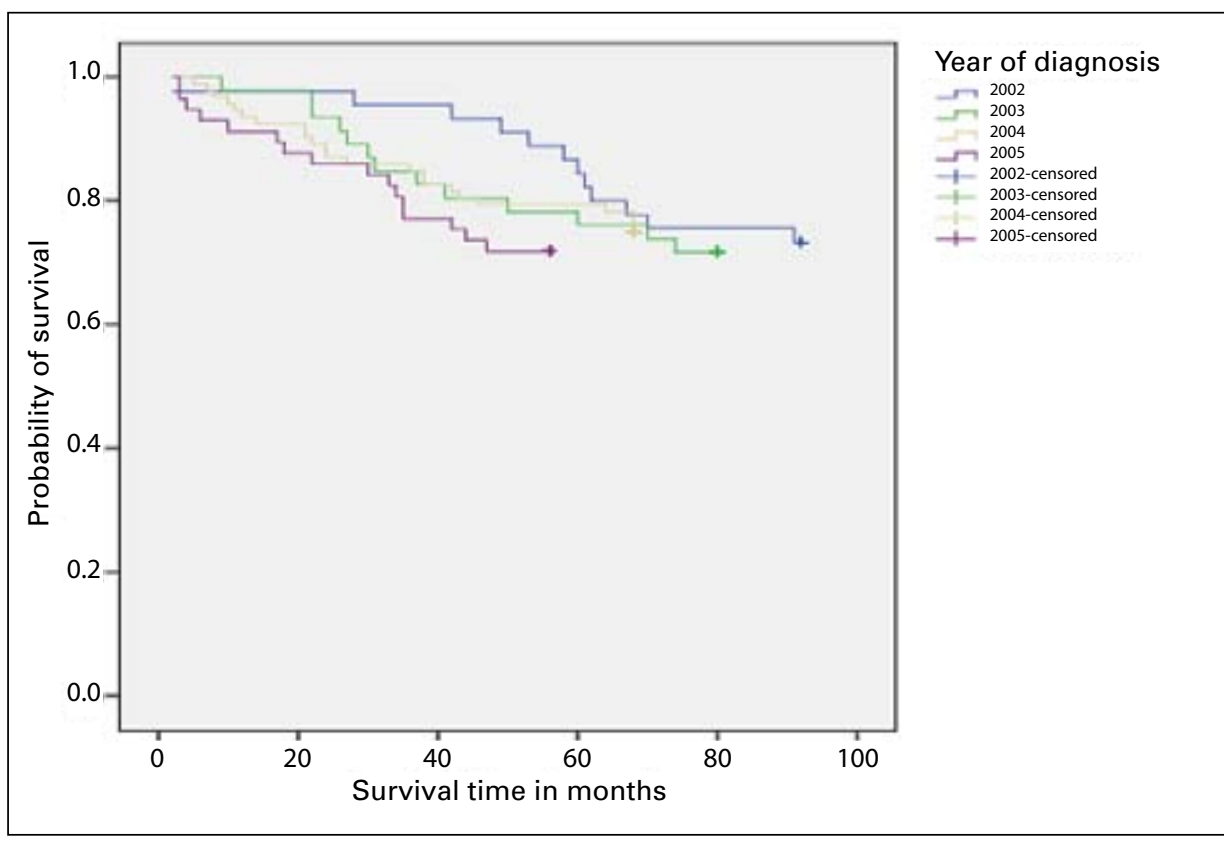

Fig. 1. Kaplan-Meier survival curves for the years 2002, 2003, 2004 and 2005.

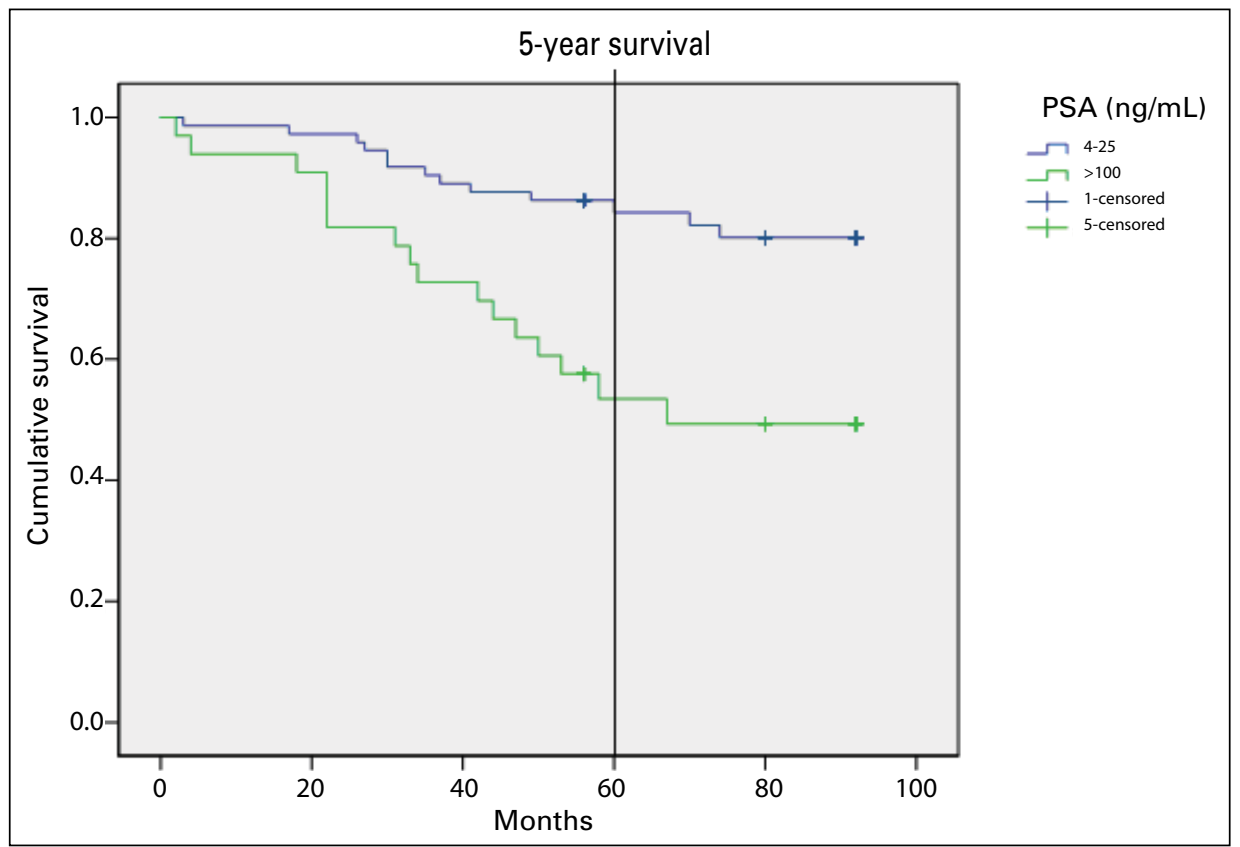

Fig. 2. Kaplan-Meier survival curves by prostate-specific antigen level.

We classified PSA first into 5 categories: 4-25; 26-50; 51-75; 76-100; and $>100$. We also included 2 categories: 4-100 and $>100$. A bimodal distribution of PSA levels was found; the first peak occurred at the $4-25 \mathrm{ng} / \mathrm{mL}$ range and the second at $>100$ range for each year of the study. The highest number of cases of occurred in patients who had a PSA between 4 and $25 \mathrm{ng} / \mathrm{mL}$ and $>100 \mathrm{ng} / \mathrm{mL}$.

Kaplan-Meier survival curves using aggregate data showed that participants with high PSA levels (>100 ng/
$\mathrm{mL}$ ) have lower survival rates (Fig. 2). The survival rate at 5 years was $55 \%$ in patients with a PSA of $>100 \mathrm{ng} / \mathrm{mL}$ compared with a survival rate of $83 \%$ in patients with a PSA of 4 to $25 \mathrm{ng} /$ $\mathrm{mL}$; this difference was highly significant (log-rank test, $p<0.001)$. Further, the risk of mortality was nearly 3 -fold in patients who had a PSA of $>100 \mathrm{ng} /$ $\mathrm{mL}$ after adjusting for age and Gleason score (Table 3). Finally, we plotted survival curves for three categories of Gleason Score $(2-4 ; 5-7 ; 8-10)$ and found lower survival rates in patients with a Gleason score of 8 to 10 for each year of study.

\section{Discussion}

The main finding of the study was 3 -year survival rates in patients diagnosed with PCa for the years 2002, 2003, 2004 and 2005 was $95 \%, 85 \%$, $85 \%$ and $78 \%$, respectively. Five-year survival rates for the same years were $88 \%, 78 \%, 77 \%$ and $72 \%$, respectively. In 2003, McDavid and colleagues reported 3-year survival rates of $83 \%$, in Kentucky, United States. ${ }^{20}$ In 2007, Merglen and colleagues reported a 5 -year survival rate of $86 \%$ for patients managed with watchful waiting. ${ }^{21}$ Our findings are consistent with these findings. However, we found both 3 -year and 5-year survival rates were declining over the period 2002 to 2005 to the extent that there was a significant difference in survival rates for the years 2002 and 2005 (log-rank test, $p=0.032$ ). This finding was not related to PSA levels as PSA levels, particularly the categories 4 to $25 \mathrm{ng} / \mathrm{mL}$ and $>100 \mathrm{ng} / \mathrm{mL}$, were similarly distributed (43\% vs. $47 \%$ ) in 2002 and 2005. Likewise, the proportion of patients with a Gleason between 8 and 10 was similar in both years (25\% vs. $26 \%)$. These findings suggest that the difference cannot be accounted for by more advanced disease in 2005. Artifactual causes, such as newly introduced interventions (therapeutic or surgical), changes in diagnostic methods, new screening strategies or increased awareness locally or nationally, can also be ruled out. The explanation for this difference may be linked to an increase in comorbid conditions. 
Mungrue et al.

Table 2. Characteristics of the sample, per year

\begin{tabular}{|c|c|c|c|}
\hline 2002 & No. $(\%)$ & PSA (ng/mL) & PCa n (\%) \\
\hline \multicolumn{4}{|c|}{ Age at enrolment (years) } \\
\hline $30-50$ & $1(2 \%)$ & $4-25$ & $20(43 \%)$ \\
\hline $51-70$ & $20(43 \%)$ & $26-50$ & $5(11 \%)$ \\
\hline$\geq 71$ & $26(55 \%)$ & $51-75$ & $17(36 \%)$ \\
\hline Total & $47(100 \%)$ & $76-100$ & $3(6 \%)$ \\
\hline Race/ethnicity & & $>100$ & $13(28 \%)$ \\
\hline East Indian & $14(30 \%)$ & & \\
\hline African & $28(60 \%)$ & & \\
\hline Other & $5(10 \%)$ & & \\
\hline Total & $47(100 \%)$ & & \\
\hline \multicolumn{4}{|l|}{ Gleason score } \\
\hline $2-4$ & $16(34 \%)$ & & \\
\hline $5-7$ & $19(40 \%)$ & & \\
\hline $8-10$ & $12(26 \%)$ & & \\
\hline Total & $47(100 \%)$ & & \\
\hline \multicolumn{4}{|c|}{ PSA (ng/mL) level by category n (\%) } \\
\hline $4-100$ & $34(72 \%)$ & & \\
\hline$>100$ & $13(28 \%)$ & & \\
\hline Total & $47(100 \%)$ & & \\
\hline 2003 & No. (\%) & PSA (ng/mL) & PCa n (\%) \\
\hline \multicolumn{4}{|c|}{ Age at enrolment (years) } \\
\hline $30-50$ & $0(0 \%)$ & $4-25$ & $26(59 \%)$ \\
\hline $51-70$ & $19(43 \%)$ & $26-50$ & $3(7 \%)$ \\
\hline$\geq 71$ & $25(57 \%)$ & $51-75$ & $2(5 \%)$ \\
\hline Total & $44(100 \%)$ & $76-100$ & $5(11 \%)$ \\
\hline Race/ethnicity & & $>100$ & $8(18 \%)$ \\
\hline East Indian & $14(32 \%)$ & & \\
\hline African & $24(54 \%)$ & & \\
\hline Other & $6(14 \%)$ & & \\
\hline Total & $44(100 \%)$ & & \\
\hline \multicolumn{4}{|l|}{ Gleason score } \\
\hline $2-4$ & $12(27 \%)$ & & \\
\hline $5-7$ & $21(48 \%)$ & & \\
\hline $8-10$ & $11(25 \%)$ & & \\
\hline Total & $44(100 \%)$ & & \\
\hline \multicolumn{4}{|c|}{ PSA (ng/mL) level by category $n(\%)$} \\
\hline $4-100$ & 37 (84\%) & & \\
\hline$>100$ & $7(16 \%)$ & & \\
\hline Total & $44(100 \%)$ & & \\
\hline 2004 & No. (\%) & PSA (ng/mL) & PCa n (\%) \\
\hline \multicolumn{4}{|c|}{ Age at enrolment (years) } \\
\hline $30-50$ & $1(1 \%)$ & $4-25$ & $46(49 \%)$ \\
\hline $51-70$ & $40(43 \%)$ & $26-50$ & $9(10 \%)$ \\
\hline$\geq 71$ & $53(56 \%)$ & $51-75$ & $5(5 \%)$ \\
\hline Total & $94(100 \%)$ & $76-100$ & $8(9 \%)$ \\
\hline Race/ethnicity & & $>100$ & $25(27 \%)$ \\
\hline East Indian & 17 (18\%) & & \\
\hline African & 64 (68\%) & & \\
\hline Other & $13(14 \%)$ & & \\
\hline Total & $94(100 \%)$ & & \\
\hline
\end{tabular}




\begin{tabular}{|c|c|c|c|}
\hline \multicolumn{4}{|l|}{ Gleason score } \\
\hline $2-4$ & $28(20 \%)$ & & \\
\hline $5-7$ & $44(47 \%)$ & & \\
\hline $8-10$ & $14(15 \%)$ & & \\
\hline Total & $94(100 \%)$ & & \\
\hline \multicolumn{4}{|c|}{ PSA (ng/mL) level by category $n(\%)$} \\
\hline $4-100$ & $69(73 \%)$ & & \\
\hline$>100$ & $25(27 \%)$ & & \\
\hline Total & $94(100 \%)$ & & \\
\hline 2005 & No. (\%) & PSA (ng/mL) & PCa n (\%) \\
\hline \multicolumn{4}{|c|}{ Age at enrolment (years) } \\
\hline $30-50$ & $2(4 \%)$ & $4-25$ & $26(47 \%)$ \\
\hline $51-70$ & $26(46 \%)$ & $26-50$ & $8(14 \%)$ \\
\hline$\geq 71$ & $29(50 \%)$ & $51-75$ & $7(12 \%)$ \\
\hline Total & $57(100 \%)$ & $76-100$ & $5(8 \%)$ \\
\hline Race/ethnicity & & $>100$ & $11(19 \%)$ \\
\hline East Indian & $8(14 \%)$ & & \\
\hline African & $39(68 \%)$ & & \\
\hline Other & $10(18 \%)$ & & \\
\hline Total & $57(100 \%)$ & & \\
\hline \multicolumn{4}{|l|}{ Gleason score } \\
\hline $2-4$ & $11(19 \%)$ & & \\
\hline $5-7$ & $30(53 \%)$ & & \\
\hline 8-10 & $16(28 \%)$ & & \\
\hline Total & $57(100 \%)$ & & \\
\hline \multicolumn{4}{|c|}{ PSA (ng/mL) level by category $n(\%)$} \\
\hline $4-100$ & $46(81 \%)$ & & \\
\hline$>100$ & $11(19 \%)$ & & \\
\hline Total & $57(100 \%)$ & & \\
\hline
\end{tabular}

Cardiovascular disease is the leading cause of death in Trinidad and hypertension is more common in Africans than South East Asians. In addition, Trinidad has the highest prevalence of diabetes in the western hemisphere and is more common in South East Asians than Africans. One possible contributing factor is screening; this raises the issue of whether screening for PCa is appropriate to reduce mortality. In the United States, the reduction in mortality has been attributed to screening, although there is no evidence. ${ }^{22,23}$ However, two recent landmark trials (the European Randomized Study of Screening for Prostate Cancer (ERSPC) ${ }^{24}$ and the US-based Prostate, Lung, Colorectal, and Ovarian (PLCO) Cancer Screening Trial ${ }^{25}$ ) have shown a small survival benefit for screening, but there remains a potential risk of overdiagnosis and overtreatment.

An important epidemiological feature of PCa in Trinidad is the large ethnic disparity between Africans (68\%) and South East Asians (14\%). Our findings support the emerging global pattern of the disproportionate burden of PCa among men of African ancestry. More importantly, we identify a unique population in which two diaspora are at the opposite ends of the PCa epidemiological spectrum. Such coexistence at the extreme ends of the spectrum is rare in a confined geographical location and presents opportunities for further investigation. In addition, this finding presents a dilemma because there are no primary prevention strategies for PCa. An approach to reducing the racial disparity in stage and survival may require offering Africans earlier and more aggressive screening, although there are no data from randomized controlled trials demonstrating that screening decreases the proportion of advanced-stage disease or reduces mortality. Further research needs to be directed at identifying biologic markers and genetic susceptibility factors, as well as additional socioeconomic factors, including use of health care systems, distance from health care, diet, literacy and health beliefs, to inform appropriate interventions.

Another important finding of the study was the link between PSA level and mortality. Patients with a PSA level of $>100 \mathrm{ng} / \mathrm{mL}$ had a 5 -year survival rate of $55 \%$ compared with patients with PSA level of 4 to $25 \mathrm{ng} / \mathrm{mL}$ with a 5 -year survival rate of $83 \%$; this difference was statistically significant (log-rank test, $p<0.001)$. In addition, we performed a 


\begin{tabular}{|c|c|c|}
\hline Risk factor & Hazard ratio $(95 \% \mathrm{Cl})$ & Significance \\
\hline Age ( >60 years) & $1.2(0.34-4.09)$ & 0.588 \\
\hline Ethnicity (African) & $1.2(0.70-2.11)$ & 0.495 \\
\hline $\mathrm{GLN}^{*}(>5)$ & $1.5(0.70-3.15)$ & 0.310 \\
\hline PSA (>100) & $3.3(1.89-5.82)$ & 0.001 \\
\hline
\end{tabular}

Cox regression analysis to predict the survival experience on the independent variables of age, ethnicity, PSA level and Gleason score. We found that only PSA level was a significant predictor of survival (HR 3.3, 95\% Cl, 1.89-5.82) such that there was a 3.3 -fold greater risk of mortality in patients with a PSA level $>100 \mathrm{ng} / \mathrm{mL}$ compared to the other groups. Age and ethnicity were not predictors of survival outcomes. Generally, patients with a high tumour burden do poorly than patients with a low tumour burden irrespective of treatment regimen. As prognosis depends on the disease burden at diagnosis (which is influenced by more metastases on bone scan, high concentrations of bone-turnover markers and raised PSA concentration), we recommend the use of PSA levels as a strong prognostic indicator, especially in our setting in which the latter is often the only one performed. ${ }^{26-28}$ We propose the development of prognostic risk groups based on variables, such as clinical T stage, serum concentrations of PSA and biopsy grade or Gleason score and the creation of nomograms for which the 5-year outcome after various treatments can be related to each patient's characteristic.

When patients were stratified by PSA levels we found an unusual distribution of cases. The distribution was bimodal such that larger number of patients were found in the 4 to $25 \mathrm{ng} / \mathrm{mL}$ or the $>100 \mathrm{ng} / \mathrm{mL}$ strata. In recent years, screening awareness has resulted in an increase in the number of men being screened at an earlier age. Therefore, early detection may be responsible for the large number of PCa cases seen in the 4 to $25 \mathrm{ng} / \mathrm{mL}$ range. On the other hand, in the $>100 \mathrm{ng} / \mathrm{mL}$ group the higher number of prostate cancer patients may be attributed to men who choose not to be screened at an early age; these men therefore present with more advanced disease and higher PSA levels. In regard to patients with PSA levels in the gap between 26 and $100 \mathrm{ng} / \mathrm{mL}$, the smaller number of cases observed are patients who were not screened and would have remained relatively asymptomatic for PCa.

Many of our findings, particularly the relationship between Gleason scores and survival and PSA levels and survival, have been well-established in the literature. The relevance of this study is the very different PCa occurrence in the two major ethnic groups, as well the increasing mortality rates between the years 2002 and 2005.
A major limitation of our study, particularly in our setting, was the unavailability of all relevant data, particularly PSA and Gleason scores. This resulted in some cases $(<5 \%)$ not being included in the analysis. Some patient records were lost due to mismatched identification numbers and names such that their medical records could not be retrieved. The issue of the accuracy in determining the true Gleason grade in a biopsy was also considered. Unfortunately, errors in the predicted biopsy Gleason score are common. Gleason grading and scoring are largely subjective, and since not all pathologists may be equally proficient in reading Gleason grades, especially on the small thin-needle core tissue samples obtained at biopsy, observer variation does occur.

\section{Conclusion}

This is the first study of its kind to provide evidence of survival rates among patients with PCa in Trinidad. In addition, the epidemiological features PCa in Trinidad at the beginning of the millennium show an average age of occurrence of 71 (range: 34-89). It is more common among African men than in other ethnic groups. A PSA of $>100 \mathrm{ng} / \mathrm{dL}$ was associated with a 3-fold higher risk of death. A Gleason score between 8 and 10 was also associated with a lower survival rate. Therefore, $\mathrm{PCa}$ remains an important contributor to morbidity and mortality for men in Trinidad. Unfortunately, the existing treatments, as well as surgical approaches, have not been fully effective to prevent or treat PCa.

Competing interests: None declared.

This paper has been peer-reviewed.

\section{References}

1. Jensen $\mathrm{OM}$, Estève $\mathrm{J}$, Moller $\mathrm{H}$, et al. Cancer in the European community and its member states. Eur $J$ Cancer 1990;1167-256.

2. Parkin DM, Bray F, Ferlay J, et al. Global cancer statistics, 2002. CA Cancer J Clin 2005;55:74-108.

3. Boyle P, Ferley J. Cancer incidence and mortality in Europe, 2004. Ann Oncol 2005;16:481-8.

4. Ferley J, Bray F, Pisani P, et al. Cancer incidence, mortality and prevalence worldwide. Version 1.0. IARC Cancer Base No. 5 book. Lyon:IARC Press; 2001.

5. Data on Prostate Cancer in Trinidad \& Tobago. Prostate Cancer International. http://pccaribbean.wordpress.com/site-map/trinidad-tobago/data/. Accessed October 17, 2011.

6. Mettlin CJ, Murphy GP, Ho R, et al. The National Cancer Data Base report on longitudinal observations on prostate cancer. Cancer 1996:77:2162-6.

7. Pienta KJ, Esper PS. Risk factors for prostate cancer. Ann Intern Med 1993;1 18:793-803.

8. Cancer in Trinidad and Tobago 2000-2002. Dr. Elizabeth Quamina Cancer Registry Report, National Cancer Report of Trinidad and Tobago. www.health.gov.tt/downloads/Downloadltem.aspx?id=29. Accessed October 17, 2011.

9. Ayoung-Chee P, Goetz L, Rampaul M. Indo-Trinidadians with prostate cancer within South-West, Trinidad and Tobago: A comparative study with Afro-Trinidadians. CURA Annual Conference Magazine 1997;25.

10. Belldegrum A, Kirby RS, Oliver RTD. New Perspectives in Prostate Cancer. England: Isis Medical Media Ltd; 1999:55. 
11. Ross RJ, Schottenfeld D. Cancer Epidemiology and Prevention. $2^{\text {nd }}$ edition. Oxford: Oxford University Press, 1996:1180-206.

12. Kolonel LN, Altshuler D, Henderson BE. The Multiethnic cohort study: exploring genes, lifestyle and cancer risk. Nat Rev Cancer 2004;4:519-27.

13. Lesko SM, Rosenberg L, Shapiro S. Family history and prostate cancer risk. Am J Epidemiol 1996:1041-7.

14. Cerhan JR, Parker AS, Putnam SD. Family history and prostate cancer risk in a population-based cohort of lowa men. Cancer Epid. Biomarkers Prev 1999;53-60.

15. Gronberg H. Prostate cancer epidemiology. Lancet 2003;361:859-64.

16. Nam RK, Fleshner N, Rakovitch E, et al. Prevalence and patterns of the use of complementary therapies among prostate cancer patients: an epidemiological analysis. J Urol 1999;161:1521-4.

17. Lippman SM, Klein EA, Goodman PJ, et al. Effect of selenium and vitamin E on risk of prostate cancer and other cancers: the Selenium and Vitamin E Cancer Prevention Trial (SELECT) JAMA 2009;301:39-51

18. Coard KC, Skeete DH. A 6-year analysis of the clinicopathological profile of patients with prostate cancer at the University Hospital of the West Indies, Jamaica. BJU Int 2009;103:1482-6.

19. Robertson CN, Paulson DF. Radical surgery versus radiation therapy in early prostatic carcinoma. Acta Oncol 1991;30:239-42. doi: 10.3109/02841869109092360.

20. McDavid K, Tucker TC, Sloggett A, et al. Cancer Survival in Kentucky and Health Insurance Coverage. Arch Intern Med 2003;163:2135-44.

21. Merglen A, Schmidlin F, Fioretta G, et al. Short- and Long-term Mortality With Localized Prostate Cancer. Arch Intern Med 2007;167:1944-50.
22. Mettlin C. Impact of screening on prostate cancer rates and trends. Microsc Res Tech 2000;51:415-8.

23. Potosky AL, Fever EJ, Levin DL. Impact of screening on incidence and mortality of prostate cancer in the United States. Epidemiol Rev 2001;23:181-6.

24. Schröder FH, Hugosson J, Roobol MJ, et al. Screening and prostate-cancer mortality in a randomized European study. N Engl J Med 2009;360:1320-8.

25. Andriole GL, Crawford ED, Grubb III RL, et al. Mortality results from a randomized prostate-cancer screening trial. N Engl J Med 2009;360:1310-9. Epub 2009 Mar 18. Erratum in: N Engl J Med 2009;360:1797.

26. Jorgensen T, Muller C, Kaalhus 0 , et al. Extent of disease based on initial bone scan: important prognostic predictor for patients with metastatic prostate cancer. Experience from the Scandinavian Prostatic Cancer Group No.2 (SPCG-2). Eur Urol 1995;28:40-6.

27. Glass TR, Tanfen CM, Crawford ED, et al. Metastatic carcinoma of the prostate: identifying prognostic groups using recursive partitioning. J Urol 2003;169:149-64.

28. Brasso K, Chistensen IJ, Johansen JS. Prognostic values of PINP, bone alkaline phosphatase CTX-I and YKL-40 in patients with metastatic prostate carcinoma. Prostate 2006;66:503-13.

Correspondence: Dr. Kameel Mungrue, Department of Paraclinical Sciences, Faculty of Medical Sciences, The University of the West Indies, St Augustine, Trinidad and Tobago; kameel.mungrue@sta.uwi.edu 